\title{
A BELEZA SECA: ASPECTOS DO PAISAGISMO NO SEMIÁRIDO BRASILEIRO
}

\author{
THE DRY BEAUTY: ASPECTS OF LANDSCAPING IN BRAZILIAN SEMIARID
}

\author{
Manoel Messias Coutinho Meira (IFBA); \\ Christiane Rayana Teixeira Silva (IFBA); \\ Lara de Oliveira Carvalho (IFBA); \\ Marília Aguiar Rodrigues (IFBA); \\ Matheus Dutra Brasil (IFBA); \\ Polyane Alves Santos, M.Sc. (IFBA)
}

\author{
Palavras Chave \\ Crise hídrica; Paisagismo; Semiárido
}

\section{Key Words}

Water crisis; Landscaping; Semiarid

\section{RESUMO}

A conservação dos escassos recursos hídricos na região Nordeste do Brasil exige um programa de gerenciamento mais eficiente. A má distribuição pluvial na localidade, a urbanização e as secas periódicas intensificam a demanda por água. Entretanto, a ocupação urbana ainda modifica a morfologia espacial sem se atentar para o potencial paisagístico natural, enquanto busca reproduzir padrões estéticos externos e distintos. Diante disso, faz-se necessária a percepção da urgência de minimizar o desperdício de água. Remodelar a paisagem através de planejamento e modificações adequadas não só ajudam a reduzir seu consumo, mas também os custos com sua manutenção. Nesse sentido, o presente trabalho apresenta soluções paisagísticas mais eficientes em termos de economia hídrica e combate à desertificação na região semiárida brasileira. Técnicas como ordenamento da flora por necessidade de água, elaboração de oásis artificiais, utilização de mantas e quebra-ventos demonstram eficiência quando aliados aos mecanismos de sobrevivência inerentes à vegetação nativa.

\section{ABSTRACT}

The conservation of scarce water resources in Northeast region of Brazil requires a more efficient management program. The bad rainfall distribution on site, urbanization and periodic droughts intensify the water demand. However, the urban occupation still modifies the spatial morphology without noticing the natural landscaping potential, while seeking to reproduce aesthetic external and different patterns. Therefore, it is necessary the perception of the urgency of minimize the waste of water. Reshaping the landscape through suitable planning and modifications not only help reduce its consumption, but also maintenance costs. Thus, the present work presents more efficient landscaping solutions with regard to water economy and fight against desertification in Brazilian semiarid region. Techniques such as plant sorting due to the water need, elaboration of artificial oasis, using mulches and windbreaks demonstrate efficiency when allied to the survival mechanisms inherent to native vegetation. 


\section{INTRODUÇÃO}

O bioma da caatinga é frequentemente apresentado como um ambiente pobre, sem vida e seco, entretanto é um mito fortalecido pelo pouco conhecimento científico e social desta unidade geográfica. A região abrange cerca de $850 \mathrm{mil} \mathrm{km}^{2}$ do Nordeste e parte do norte de Minas Gerais, o que corresponde a 10\% do território brasileiro. Além disso, de acordo com Magalhães (2012), é o único bioma exclusivamente brasileiro, possuindo riqueza particular em termos de biodiversidade e fenômenos característicos.

A irregularidade das chuvas e sua má distribuição são marcantes na caatinga, bem como os solos rasos, secos e ocasionalmente com afloramentos rochosos, que contribuem decisivamente para o aumento da biodiversidade. A precipitação varia entre $250 \mathrm{~mm}$ ano e $1.000 \mathrm{~mm}$ ano concentrados em dois ou três meses, entretanto a taxa de evaporação é cerca de $2.000 \mathrm{~mm}$ ano-1 (MAGALHÃES, 2012).

Com os longos períodos de estiagem causados pela evaporação intensa, a vegetação xerófita - formação vegetal seca - se tornou dominante devido aos seus mecanismos de sobrevivência à falta de água. Dentre as adaptações florísticas ao semiárido destacam-se as folhas pequenas, sua queda nos períodos mais secos, no caso das caducifólias, ou a sua substituição por espinhos, no caso das espinhosas; maneiras de evitar a perda de água por transpiração em excesso.

A temporariedade da vegetação herbácea, o estado esbranquiçado que adquirem as plantas na estiagem e o mito da pobreza em biodiversidade colaboram para que a caatinga seja pouco explorada em termos paisagísticos. Mesmo nas cidades do semiárido, nos espaços urbanos não é comum encontrar plantas nativas, mas sim um tipo de vegetação mais exigente em termos de nutrientes e água. Essa vegetação exigente tende a permanecer vívida durante todo o ano em seu habitat natural e, por esse motivo, compõe as paisagens mais tradicionais ou convencionais por sua plasticidade.

O paisagismo é, para Limberger e Santos (2000), uma ciência e uma arte que estuda o ordenamento do espaço exterior em função das necessidades atuais e futuras, e dos desejos estéticos do homem. Dessa forma, a fim de contornar a escassez de água, algumas técnicas paisagísticas podem ser implementadas para reduzir a necessidade do uso e manutenção de água enquanto se vale do potencial estético da caatinga.

Nesse sentido, Xeriscape é um termo que foi concebido e registrado por uma força-tarefa do Departamento de
Denver, nos Estados Unidos, em 1978, e se refere à jardinagem apropriada ao clima mais árido. A palavra provém do grego xeros, que significa seco, e do inglês landscape, que significa paisagem (HEIGHTOWER, 2017). Esse tipo de jardinagem é amplamente difundido nos EUA e busca promover o uso racional da água, respeitando as condições ambientais nos locais mais secos. Contudo, tanto no setor público quanto no privado do Brasil, não há tradição do uso de técnicas paisagísticas que amparam a escassez de água.

Historicamente, os europeus foram os principais responsáveis pela colonização do Brasil, modificando assim a forma de viver dos nativos. Tais influências trouxeram costumes e padrões estéticos que perduram até a atualidade. A presença estrangeira foi reforçada, como afirma Pereira (2009), pelo fato de que um povo economicamente dependente passa a produzir cultura dependente. Conforme transformações ocorreram na sociedade moderna, embora a realidade brasileira não seguira os moldes da europeia, houve esforços para acompanhar as tendências externas.

O modelo de jardim europeu tradicional só foi de fato rompido quando o paisagista Roberto Burle Marx, entre os anos de 1930 e 1940, segundo Macedo (2003), criou o jardim modernista, trazendo espécies da paisagem local como bromélias, filodendros e epífitas para o contexto brasileiro. Do ponto de vista estético, ele deixou de lado o formalismo, a rigidez e a simetria dos jardins barrocos e românticos. Entretanto, após Burle Marx uma lacuna se estabeleceu entre o paisagismo do semiárido e o resto do País, dada singularidade da região que não acolheu as vistosas plantas tropicais provenientes das regiões mais úmidas.

Os espaços exteriores verificados neste trabalho, são os espaços livres públicos das praças, que desempenham importante papel nas cidades. Além da integração e sociabilidade, elas melhoram as condições ambientais locais, amenizando a temperatura, atenuando os efeitos do vento e valorizando a paisagem local. Viero e Barbosa Filho (2009) afirmam que o contato com o verde e o uso do espaço para o convívio social influencia positivamente no psicológico da população, fornecendo bem-estar e qualidade de vida aos que desfrutam do ambiente. Entretanto, enquanto possuem caráter mais forte de zona de circulação nas grandes cidades, as praças significam, para os municípios de médio e pequeno porte, locais mais voltados para o descanso e confraternização.

Além das praças, a morfologia urbana na região nordeste ainda é fortemente influenciada pela ocupação 
elitizada do espaço, seja pela estrangeira ou pelas grandes cidades brasileiras. Nessa perspectiva, o presente trabaIho busca apresentar soluções paisagísticas na produção mais própria do espaço semiárido nordestino, que possui características singulares, porém pouco aproveitadas.

\section{METODOLOGIA}

Para verificar os aspectos que compõem o semiárido nordestino, o estudo se baseou em uma pesquisa com referencial teórico essencialmente bibliográfico. Segundo Tachizawa e Mendes (2006), a pesquisa teórica busca, em geral, compreender ou proporcionar um espaço para discussão de um tema ou uma questão intrigante da realidade.

A pesquisa é qualitativa, de caráter exploratório, em que a partir da contextualização do cenário da seca, buscou-se sintetizar e apresentar técnicas paisagísticas para conciliar as composições visuais ao manejo e à economia de água.

\section{RESULTADOS E DISCUSSÃO}

O paisagismo no semiárido nordestino é singular em consequência da abundância de espécies nativas que podem ser utilizadas formando uma unidade floristicamente diversa e bela. Contudo, a população local enxerga que a representação da caatinga no espaço público significa diminuir o potencial estético do local. Os componentes naturais podem ser mal interpretados como um retrocesso civilizatório, indo de encontro à ideia de correspondência com os padrões externos avaliados como superiores.

Como referência, em Petrolina - $\mathrm{PE}$, as praças 21 de Setembro e Maria Auxiliadora foram submetidas a projetos de revitalização em 2011 que inseriram nas praças históricas elementos do semiárido como cactos, xique-xiques e outros adornos. A repercussão foi negativa por parte da população, os projetos não foram concluídos e após seguidos atos de vandalismo novos projetos foram elaborados. A Figura 1 ilustra a Praça Maria Auxiliadora em dois diferentes ângulos.

Os esforços para modificar a paisagem, através de um manejo artificial são custosos e pouco duradouros, pois o estresse a que são submetidas as plantas exóticas não corresponde ao seu padrão natural. As altas temperaturas, luminosidade e evaporação rápida desgastam a paisagem com velocidade e, como consequência, paisagens tradicionais no semiárido exigem grandes quantidades de água e manutenção.

No planejamento paisagístico é necessário levar em consideração características locais como volume das

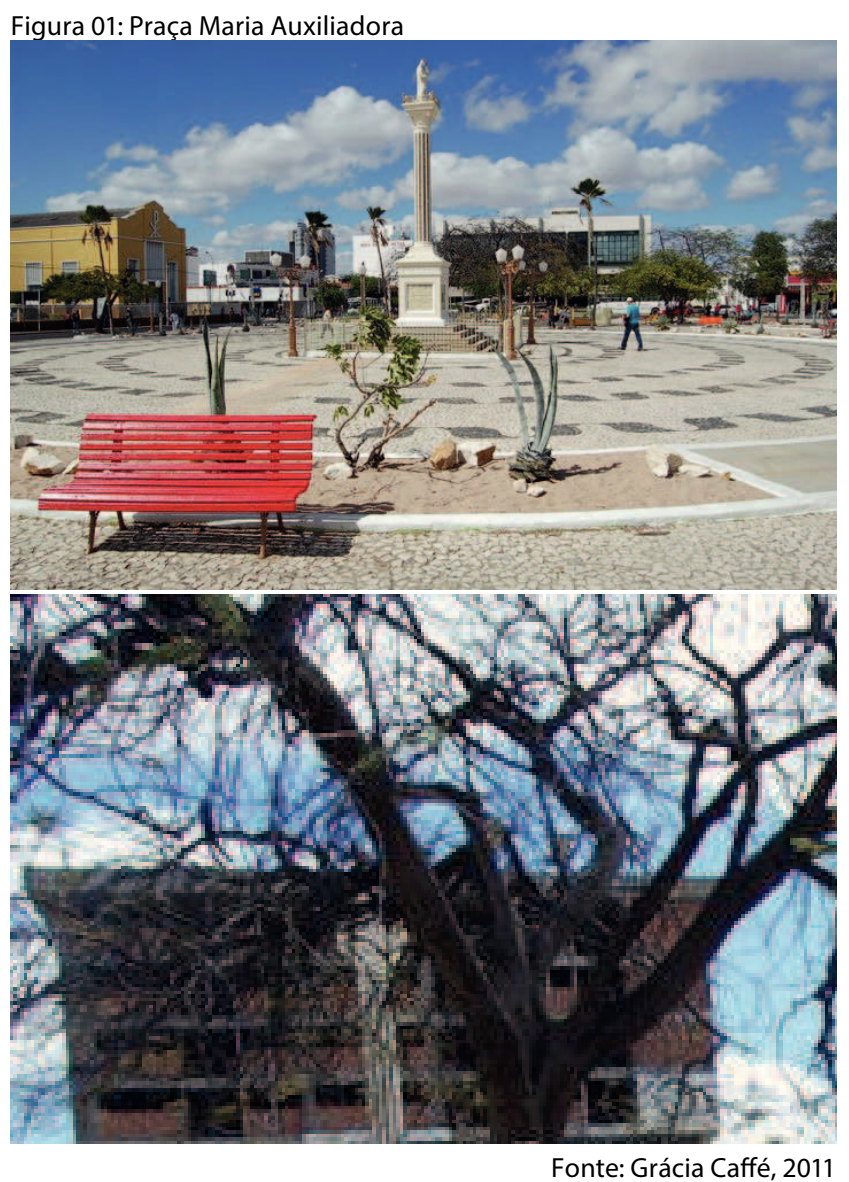

precipitações pluviométricas, qualidade do solo e altitude a fim de selecionar a vegetação a ser utilizada no sítio. Em alguns casos, porém, a vegetação nativa não será a escolha mais apropriada, pois o desenvolvimento do homem no espaço pode alterar significativamente o microclima e a topografia de uma região. As ações antrópicas podem conceber locais mais secos, como estacionamentos, mais úmidos, como bacias de retenção, ou artificialmente sombreados.

A rejeição à estética local demonstra a forte influência externa que ainda é pertinente, fato que corrobora o preconceito com a própria cultura, mesmo que de forma indireta. Uma maneira para satisfazer o desejo por paisagens convencionais e aproximar as pessoas da necessidade de economizar água é utilizar a aproximação da ideia de oásis. A técnica consiste em apenas utilizar plantas tradicionais que exigem mais recursos ou uma fonte hídrica nos locais com maior impacto visual como pátios, entradas ou similares.

Para manter o equilíbrio visual, é preciso criar uma zona de transição entre as plantas mais próximas do oásis, que utilizam mais água, para as naturais, que utilizam menos. O oásis na Figura 2 não utiliza uma fonte de água, mas explicita onde seu uso se concentra, 
direcionando o olhar do expectador para a área abaixo da árvore.

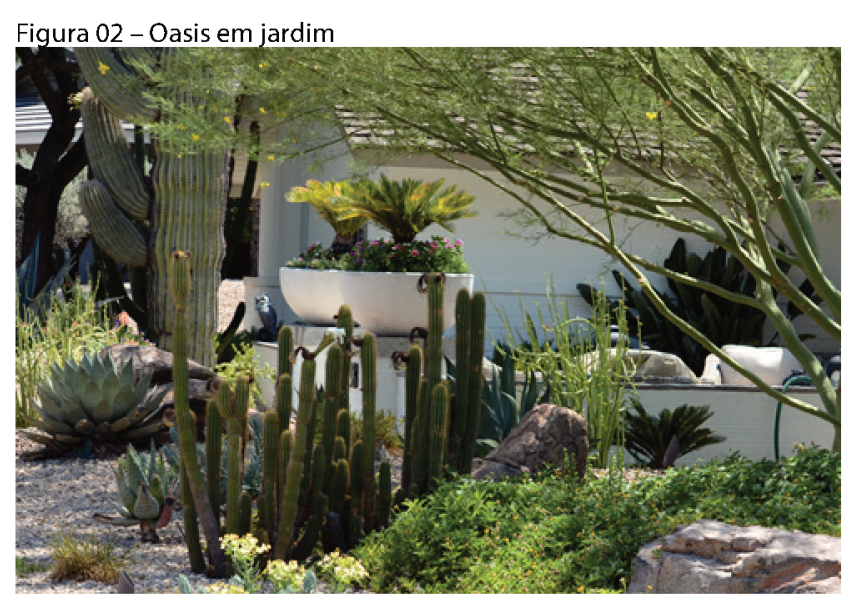

Fonte: Haley Paul, 2013

Outra maneira de melhorar a gestão hídrica na elaboração paisagística é o agrupamento de plantas na paisagem de acordo com a sua necessidade de água. $O$ agrupamento permite que sistemas o de irrigação seja partilhado, fazendo com que cada grupo de plantas receba apenas a quantidade de água que necessita. A técnica tem a vantagem adicional que plantas no mesmo local de irrigação não serão mais ou menos irrigadas mediante outras plantas.

O uso de mantas também é uma maneira eficiente para reduzir a evaporação umidade no solo, uma camada entre 4 a 5 centímetros é suficiente para criar uma barreira isolante contra intempéries, regulando a temperatura do solo, diminuindo a compactação e eliminando as ervas daninhas. As mantas podem substituir a relva em locais mais secos ou que não permitem fixação, já que não necessitam de água.

Mantas inorgânicas como de cascalho provém calor ao local, por isso sua utilização é indicada para ambientes sombreados, sem incidência solar direta. Além de manter o solo fresco, essas coberturas podem ser organizadas a fim de de criar efeitos visuais a partir das suas tonalidades, já que a jardinagem seca possui uma paleta de cores mais limitada aos tons de verde, cinza e marrom.

Em um projeto em que se almeje utilizar uma relva, algumas espécies botânicas de gramíneas mais resistentes à aridez podem ser consideradas. Gramas com excelente tolerância à seca incluem: grama-batatais (Paspalim notatum), grama-esmeralda (Zoysia japônica) e grama-bermudas (Cynodon dactylon). A grama-batatais é nativa do semiárido e quando exposta aos períodos de seca, entra em estado de dormência, voltando a se florescer quando as chuvas reiniciam. Embora sejam robustas, as plantas necessitam de cuidados, apesar de mínimos, para que não fiquem sempre com aspecto ressecado e descuidado.

Quebra-ventos podem ser formados por muros, cercas ou arbustos, e auxiliam a reduzir a velocidade do vento, o que diminui substancialmente a perda de umidade do solo e a evapotranspiração das plantas. Entretanto, França e Oliveira (2010) concluem que a pouca difusão da prática no semiárido nordestino está principalmente ligada à ausência de informações relativas ao seu custo/benefício e importância, o fracasso de experiências com quebra-ventos de aerodinâmica incorreta e o baixo nível tecnológico e de renda de muitos agricultores locais.

Os quebra-ventos devem ser muito considerados em locais onde há fortes e frequentes rajadas de vento, que além de aumentarem a evaporação, desgastam o solo causando erosão. Sua efetividade é determinada pelo tamanho, densidade e forma, possuindo a altura a maior influência. $O$ ideal é organizar a barreira em forma de degraus, sem falhas e com densidade moderada, assim o vento é direcionado sem causar grandes impactos na barreira e no solo. A Tabela 1 apresenta as espécies botânicas perenes durante todo o ano mais recomentadas para formação dos quebra-ventos no semiárido, considerando a sua inserção no contexto urbano.

Tabela 01: Espécies vegetais recomendadas

\begin{tabular}{|c|c|c|}
\hline Espécie & Porte & Características \\
\hline Acácia spp. & Alto & Zonas semiáridas \\
\hline $\begin{array}{l}\text { Bambusa } \\
\text { oldhamii } \\
\text { (bambu) }\end{array}$ & Alto & $\begin{array}{l}\text { Flexibilidade } \mathrm{e} \\
\text { usos econômicos }\end{array}$ \\
\hline Eucalyptus spp. & Alto & Zonas semiáridas \\
\hline $\begin{array}{l}\text { Hibiscus l. } \\
\text { (hibisco) }\end{array}$ & Médio & $\begin{array}{l}\text { Crescim en to } \\
\text { rápido }\end{array}$ \\
\hline $\begin{array}{l}\text { Leucaena } \\
\text { leucocephala } \\
\text { (leucena) }\end{array}$ & Médio & Zonas semiáridas \\
\hline $\begin{array}{l}\text { Mimosa } \\
\text { caesalpiniaefolia } \\
\text { (sabiá) }\end{array}$ & Médio & Usos econômicos \\
\hline $\begin{array}{l}\text { Pennicetum sp. } \\
\text { (capim elefante) }\end{array}$ & Baixo & Usos econômicos \\
\hline $\begin{array}{ll}\text { Persea } & \text { sp. } \\
\text { (abacateiro) } & \\
\end{array}$ & Médio & Usos econômicos \\
\hline Pinus spp. & Alto & Solos arenosos \\
\hline
\end{tabular}


Deve-se atentar para os cuidados ao se utilizar espécies forrageiras no paisagismo, visto que a região Nordestina possui como uma de suas bases socioeconômicas a atividade agropecuária. Dessa maneira, os animais podem se alimentar das plantas que compõe a paisagem caso as devidas precauções não sejam tomadas, como o cercamento ou preferencialmente a sua não utilização caso essa possibilidade seja eminente.

O Jardim de Pedras (Figura 3), em Brumadinho - MG, segue os princípios de jardinagem mais ecológica, utilizando plantas resistentes às altas temperaturas como cactáceas, crassuláceas e euforbiáceas. Além disso, utiliza as pedras para criar caminhos e fazer contrastes, evidenciando as plantas e sua morfologia. A opção por manter o solo cru para trânsito dos visitantes aliado à disposição espaçada das plantas mais perceptíveis, agrega caráter mais natural ao jardim.

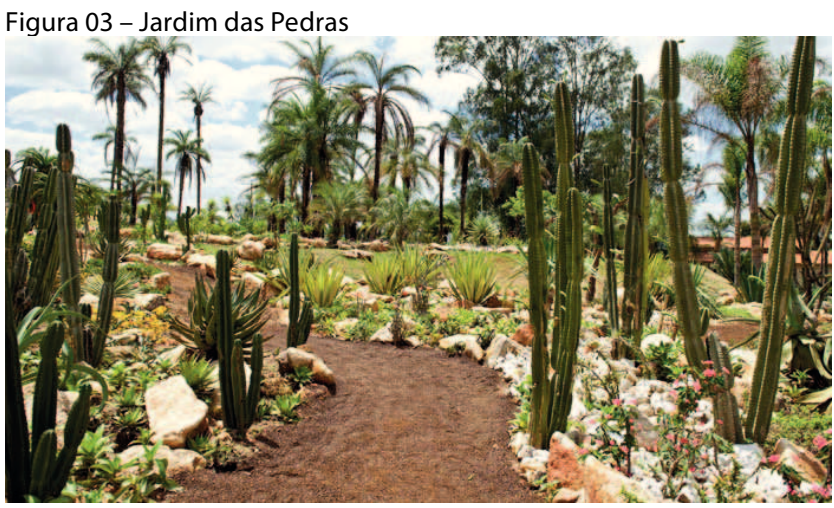

Fonte: Rossana Magri, 2014

A fertilidade do solo é garantida pela serapilheira, visto que boa parte dos nutrientes absorvidos pela planta voltam para o solo através dessa camada de folhas que acumula no chão. A utilização de fertilizantes e inseticidas em ambientes onde as plantas são adaptadas é menos frequente e mais incomum. Jardins desérticos como estes, que exploram a biodiversidade dos climas mais áridos tendem a se tornar cada vez mais comuns, pois é uma tendência crescente nos últimos anos e benéfica para o ambiente.

\section{CONCLUSÕES}

A necessidade de água no paisagismo pode ser reduzida usando princípios mais naturais de escolha da composição florística, selecionando plantas mais tolerantes à estiagem, como cactáceas, bromélias, suculentas e outras. Outras formas de conservação de água na paisagem incluem agrupamento das plantas de acordo com as suas necessidades hídricas, criação dos oásis artificiais, o uso de mantas no solo e os quebra-ventos.
O agrupamento permite economia no arranjo de irrigação e desperdício mínimo de água. Em contrapartida, oásis são medidas que almejam mitigar o preconceito dos novos jardins, reflexo da tradição estética externa. Ao mesclar as paisagens, embora mantenham as plantas nativas em segundo plano, os oásis satisfazem sem dificuldades as exigências das praças, que possuem importância social e ecológica na conjuntura urbana.

A cobertura das mantas na jardinagem ajuda na retenção de umidade e temperatura, prevenindo a erosão e bloqueando ervas-daninhas, que competem com a flora ornamental por nutrientes e água. Os quebra-ventos possuem função semelhante, protegendo o solo da erosão eólica e as plantas da evaporação desnecessária da umidade no canteiro. Todas as medidas, no entanto, precisam ser bem avaliadas antes de implantadas, pois embora as plantas da caatinga sejam resistentes, o risco de desregular o ecossistema existe.

Um ambiente balanceado começa com uma análise prévia das características locais, planejamento e seleção de plantas adequadas para o local. Um paisagismo efetivo deve combinar plantas com as características do microclima local, evitando esforços desnecessários para sua subsistência.

Ademais, a busca pela estética tradicional é um agravante para a situação da seca na caatinga, pois exige a utilização de grandes quantidades de água e fertilizantes para sua manutenção. É preciso buscar não apenas uma gestão governamental, mas também uma administração e cuidado social, possibilitando à população em geral enxergar a beleza do bioma da caatinga, o que só é possível através da utilização apropriada e eficaz dos seus recursos.

O convívio em sincronia com a caatinga permite a continuidade da vida no sertão. Assim, as novas perspectivas da seca auxiliam no combate a antigos mitos que se referem à pobreza biológica e visual do território. Dessa forma, o bioma não deve ser visto como um empecilho para o paisagismo, mas sim um componente a ser explorado.

\section{AGRADECIMENTOS}

Ao IFBA, pelo apoio e confiança.

\section{REFERÊNCIAS}

CAFFÉ, G. Praça Maria Auxiliadora. 2011. Disponível em: <caffezaletal.blogspot.com.br/2011/08/prca-maria-auxiliadora.html>. Acesso em 16 jan. 2017. 
FRANÇA, F. M. C.; OLIVEIRA, J. B. Quebra-ventos na propriedade agrícola. Cartilhas temáticas - tecnologias e práticas hidroambientais para convivência com o Semi-árido, Fortaleza, p. 21, 2010.

HALEY, P. Creating a Lush Desert Oasis in the Urban Landscape. 2013. Disponível em: <https://greenlivingaz. com/desert-oasis>. Acesso em: 18 jan. 2017.

HEIGHTOWER, S. Xeriscape. UC Master Gardener Program of Sonoma County. Universidade da Califórnia. Disponível em: <sonomamg.ucanr.edu/Feature_Articles/ Xeriscape>. Acesso em 16 mar. 2017.

LIMBERGER, L. R. L.; SANTOS, N. R. Z. Caderno Didático Paisagismo 1. Universidade Federal de Santa Maria, Santa Maria, mar. 2000.63 p.

MACEDO, S. S. O paisagismo moderno brasileiro Além de Burle Marx. Paisagens em debate, São Paulo, n. 1, out. 2003.

MAGALHÃES, T. Caatinga, ecossistema heterogêneo. IHU On-Line - Revista do Instituto Humanitas Unisinos, São Leopoldo, n. 389, p. 11-13, abr. 2012.

MAGRI, R. Jardim de Pedras. 2014. Disponível em: <inhotim.org.br/blog/jardim-de-pedras-no-inhotim>. Acesso em: 17 jan. 2017.

PEREIRA, V. A produção de imagens no Brasil e sua relação com a estética europeia: do neoclássico aos modernos de 1922. Plural: revista do programa de pós-graduação em sociologia, Tubarão, v. 1, p. 7, 2009.

TACHIZAWA, T.; MENDES, G. Como fazer monografia na prática. 12ed. Rio de Janeiro: Editora FGV, 2006.

VIERO, V. C.; BARBOSA FILHO, L. C. Praças públicas: origem, conceitos e funções. In: Jornada de Pesquisa e Extensão. Anais... ULBRA. Santa Maria, p.1-3, 2009. 